\title{
A method for prostate and breast cancer cell spheroid cultures using gelatin methacryloyl-based hydrogels
}

Christoph Meinert ${ }^{1}$, Christina Theodoropoulos ${ }^{1}$, Travis J Klein ${ }^{1}$, Dietmar W Hutmacher ${ }^{1,2,3,4}$, Daniela Loessner ${ }^{1,5}$

${ }^{1}$ Queensland University of Technology (QUT), Brisbane, QLD, Australia;

${ }^{2}$ Australian Prostate Cancer Research Centre - Queensland, Translational Research Institute, Brisbane, QLD, Australia;

${ }^{3}$ George W Woodruff School of Mechanical Engineering, Georgia Institute of Technology, Atlanta, GA, USA;

${ }^{4}$ Institute for Advanced Study, Technical University of Munich, Munich, Germany;

${ }^{5}$ Barts Cancer Institute, Queen Mary University of London, London, United Kingdom.

\section{Corresponding Author:}

Daniela Loessner

Institute of Health and Biomedical Innovation

Queensland University of Technology

60 Musk Ave, Kelvin Grove, QLD 4059

Phone: +61 731386441

Fax: +61 731386030

email: daniela.lossner@qut.edu.au

Running Head: 3D cell culture platform 


\section{i. Abstract}

Modern tissue engineering technologies have delivered tools to re-create a cell's naturally occurring niche in vitro and to investigate normal and pathological cell-cell and cell-niche interactions. Hydrogels based on biomaterials mimic crucial properties of native extracellular matrices, including mechanical support, cell adhesion sites and proteolytic degradability. As such, they are applied as 3D cell culture platform to replicate tissue-like architectures observed in vivo, allowing physiologically relevant cell behaviours. In this chapter, the latest bioengineered 3D approaches used for prostate and breast cancer are reviewed. Furthermore, the synthesis and use of gelatin methacryloyl-based hydrogels as in vitro 3D cancer model is described. This platform is used to engineer the microenvironments for prostate and breast cancer cells to study processes regulating spheroid formation, cell functions and responses to new drug candidates. Collectively, these bioengineered 3D approaches provide cell biologists with innovative pre-clinical tools that integrate the complexity of the disease seen in patients to advance our knowledge of cancer cell physiology and the contribution of a tumor's surrounding milieu.

\section{ii. Keywords}

hydrogel, prostate cancer, breast cancer, 3D model, spheroid

\section{Introduction}

Tissue-engineered constructs permit the physiological relevance of biological tissues by integrating extracellular matrix (ECM) components, different cell types, vascularisation, as well as molecular and biomechanical cues. These engineered microenvironments harbour the complexity, temporal dynamics and signalling milieu required for 3D cell culture platforms, in vitro disease models and drug screening (Abbott and Kaplan 2015). Various ECM mimics derived from natural and synthetic materials are suitable to produce scaffolds or hydrogels for 3D cell culture, allowing extracellular signalling stimuli and physiologically relevant cell functions (Rijal and Li 2016). Next to cell-matrix interactions, cell-cell communications between multiple cell types are equally important, for example the co-culture of cancer cells with cancer-associated fibroblasts and immune cells recreates immunocompetent 3D cancer models for drug discovery studies (Nyga et al. 2016).

The microenvironment surrounding a tumour has a crucial role in modulating its invasive and metastatic capacity and dissemination throughout the body to different tissues or organs, such as blood vessels, lung, bone marrow and bone. The induction of angiogenesis is not only 
required for the haematogenous dissemination of tumour cells but also for the growth of most solid tumours, including prostate and breast tumours (Joyce and Pollard 2009). Matrigel, a heterogeneous basement membrane mixture derived from Engelbreth-Holm-Swarm (EHS) mouse sarcoma, is still the most widely used in vitro system for studying tumour cell invasion, angiogenesis and metastasis (Albini 2016).

Bioengineered 3D models are sophisticated tools to model prostate and breast vascularisation. Prostate or breast cancer cells co-cultured with human umbilical vein endothelial cells (HUVECs) and mesenchymal stromal cells within star-shaped polyethylene glycol (starPEG)heparin hydrogels mimic processes occurring during tumour angiogenesis. This bioengineered tumour angiogenesis microenvironment allows cell responses to chemotherapeutics and angiogenesis inhibitors at doses that are more clinically applicable than in traditional 2D cultures and their analysis in real time compared to in vivo studies, which mostly measure endpoint anti-tumour effects (Bray et al. 2015). Moreover, the controlled modulation of this 3D cell culture platform, via integration of peptide motifs found in collagen or laminin, can be used to investigate the biochemical impact of different ECM components on prostate and breast cancer cell morphology, proliferation, invasion and angiogenesis (Taubenberger et al. 2016). While this particular tissue-engineered approach has been applied to study prostate and breast cancer cells in 3D, other biomaterial-based cell cultures have been performed to study specific aspects or components of the tumour microenvironment of both cancer entities, which is reviewed in the following sections.

\subsection{Prostate cancer}

Matrigel is commonly used as a standard in vitro model for prostate cancer, allowing the culture and long-term expansion of non-malignant and malignant prostate epithelial cells (Karthaus et al. 2014; Gao et al. 2014). As extensively reviewed elsewhere (Loessner et al. 2014), bioengineered platforms are excellent tools to delineate not only the contribution of the stromal microenvironment to tumour initiation but also metastatic progression to the bone in particular. Our group showed that the 3D co-culture of prostate cancer cells, embedded within PEG-based hydrogels, and primary human osteoblasts, seeded onto polycaprolactone-tricalcium phosphate scaffolds, mimicked paracrine interactions in vitro. Upon 3D co-culture, genes associated with the bone matrix, bone remodelling, bone growth factors, transforming growth factor $\beta$ pathway, skeletal and vasculature development were upregulated in prostate cancer cells, indicative of osteomimicry processes seen during bone metastasis (Sieh et al. 2014). 
Other 3D co-culture approaches include for example prostate cancer cells, derived from patient-derived xenografts, and murine osteoblasts within hyaluronan-based hydrogels (Fong et al. 2016). A microfluidic chamber coated with a collagen type-I hydrogel recreates the bone microenvironment of prostate cancer in vitro. Co-culture of bone metastatic prostate cancer cells with human bone marrow-derived stromal cells in this integrative system promoted a protrusive phenotype and enzyme activity detected by high-resolution imaging techniques (Bischel et al. 2014). A polyacrylamide-based hydrogel served as a scaffolding material to produce colloidal crystals that resemble the microstructure of decellularised bone to study cancer-related metastasis in immune-compromised mice. Hydrogel scaffolds seeded with primary human bone marrow-derived stromal cells were implanted subcutaneously and orthotopic prostate tumours generated to establish circulating tumour cells and blood-borne metastasis over 2 months. Importantly, this hydrogel scaffold induced the engraftment of circulating tumour cells and the serial transplantation into tumour-free murine hosts to uncover critical stromal-derived factors. The same hydrogel scaffold was also used to study breast cancer-related metastases (Bersani et al. 2014).

Several high-throughput platforms have been developed and are based on 3D cultures of prostate cancer cells grown for example in polydimethylsiloxane microwell arrays (Chambers et al. 2014) and multilayered hyaluronic acid-based hydrogels (Engel et al. 2015) to screen cell functions and responses to drugs.

\subsection{Breast cancer}

In the context of breast cancer, the role of the altered microenvironment in cancer development and progression has been correlated with in increased stiffness. In fact, tissue stiffening occurs through enhanced ECM remodelling, collagen cross-linking, activities of matrix metalloproteinases, level of lysyl oxidase, focal adhesions and integrin signalling. Standard in vitro models are based on 3D cultures of non-malignant and malignant breast cancer cells using collagen type-I hydrogels or a reconstituted basement membrane (rBM) matrix (Levental et al. 2009). To control and modulate matrix stiffness independent of ligand density in 3D, innovative 3D approaches have been developed, for example interpenetrating networks of an alginate and rBM matrix. Alginate is derived from seaweed and cross-linked via divalent cations, and the rBM matrix is basically Matrigel, which includes amongst others collagen and laminin. These interpenetrating hydrogel networks resemble the physical properties of normal and cancerous breast tissues and highlight that stiffness and matrix composition act together to promote a malignant phenotype (Chaudhuri et al. 2014). An alginate-based, oxygen-controlled 
3D tumour model showed that hypoxia-related cell responses and tumour angiogenesis are critical regulators of pro-inflammatory signalling events in the tumour microenvironment (DelNero et al. 2015).

Other 3D breast cancer models are based for example on laminin-rich ECM (lrECM) hydrogels, which have been widely used for studies of glucose metabolism and oncogenesis (Onodera et al. 2014). Chitosan-based matrices in combination with hydroxyapatite, a structural bone component, allow the modelling if breast cancer-related bone metastases in vitro (Zhu et al. 2015). A 3D platform based on aldimine cross-linked collagen type-I hydrogels was developed to screen the therapeutic efficacy of humanised monoclonal antibodies in blocking breast cancer cell proliferation and initiating apoptosis. The most potent antibody, targeting a major collagen type-I integrin receptor, was further validated in vivo and its target antigen clinically. Strikingly, the selected antibody showed no inhibitory capacity in traditional 2D cell culture conditions or Matrigel, indicating that neither recapitulates the structure of the basement membrane nor the collagen-rich interstitial matrix (Dudley et al. 2014). Interestingly, a microfluidic platform was used to study integrin-based mechanotransduction and fluid stresses in breast cancer cells embedded in collagen type-I hydrogels by simulating the interstitial fluid pressure of advanced breast tumours (Polacheck et al. 2014).

A number of high-throughput platforms are available incorporating $3 \mathrm{D}$ cultures of breast cancer cells that are maintained for example as 3D microtissues using the hanging drop system (Anastasov et al. 2015), within polyethylene glycol dimethacrylate-based hydrogel microwell arrays (Singh et al. 2016), micropatterned gelatin methacrylate-based hydrogels (Peela et al. 2016) and a microfluidic array that produces spheroid-laden alginate droplets (Sabhachandani et al. 2016). These platforms are majorly used for studies of cellular behaviour and responses to chemotherapeutics and/or radiation treatment.

The dimensionality impacts the cell mechanical properties of highly metastatic cancer cells, thereby altering cell signalling and responses to drug treatment. Using an integrated approach combining microrheology, a microfluidic device and computational modelling, differences in the intracellular mechanical properties of breast cancer cells grown in $2 \mathrm{D}$ and $3 \mathrm{D}$ within collagen type-I hydrogels were confirmed (Mak et al. 2014). Taken together, these studies further highlight that 2D cell-based assays inadequately recapitulate 3D cytoskeletal networks, mechanical characteristics, cell functions and responses to therapeutics. The accurate recreation of the dimensionality of physiological microenvironments in in vitro $3 \mathrm{D}$ cancer models is a building block to decipher pathological processes. 


\subsection{Gelatin methacryloyl (GelMA)-based hydrogels as in vitro 3D cancer models}

GelMA represents a semi-synthetic matrix combining the advantageous features of naturallyderived, e.g. Matrigel, rBM, lrECM and collagen type-I, and synthetic materials, e.g. PEG, resulting in a hydrogel system with cell binding and degradable sites represented by the native ECM, as well as high stability and tunable mechanical properties. Functionalisation of gelatin with methacryloyl groups results in a photocrosslinkable polymerisation reaction. Our group was the first to apply this bioengineered approach to grow ovarian cancer spheroids in vitro and to deliver ovarian cancer spheroids in vivo (Kaemmerer et al. 2014). We have shown that ovarian cancer spheroid formation is a function of hydrogel stiffness, resembling cancer spheroids present in the tumour fluid (ascites) within the abdominal cavity of patients with ovarian cancer. The implantation of spheroid-containing hydrogels into NOD/SCID mice caused local tumour growth and a metastatic spread as observed in patients with advanced disease. This semi-synthetic hydrogel system offers an inexpensive, reproducible and tailorable matrix for 3D cancer cell cultures to improve our understanding of disease progression on a cellular level and to screen new anti-cancer drugs (Kaemmerer et al. 2014). In addition, our group used GelMA-based hydrogels for cartilage tissue engineering due to its versatile mechanical properties (Levett et al. 2014).

In this book chapter, we report the synthesis of GelMA (section 3.1.), and, for the first time, the characterisation of the degree of amine functionalisation of GelMA (section 3.2.), as well as the suitability of GelMA-based hydrogels to grow prostate and breast cancer cell spheroids over a 3D culture period of 14 days (section 3.3.). These cancer spheroid cultures can then be utilised for a number of different bioassays to assess cell viability (section 3.4.), morphology (section 3.5.) and proliferation (section 3.6.).

\section{Materials}

\subsection{Reagents}

\subsubsection{GelMA synthesis}

- Gelatin from porcine skin, type A, 300 bloom, Sigma-Aldrich

- Methacrylic anhydride (MAAh), Sigma-Aldrich (hazardous)

- Phosphate-buffered saline (PBS), pH 7.4, Life Technologies

- Demineralised or ultrapure (MilliQ) water

- $\mathrm{NaOH}$, Sigma-Aldrich 


\subsubsection{Characterisation of GelMA functionalisation}

- 2,4,6-Trinitrobenzenesulfonic acid (TNBS), 5\% (wt/vol) solution, Sigma-Aldrich

- $\mathrm{NaHCO}_{3}$, Sigma-Aldrich

- Demineralised or ultrapure (MilliQ) water

\subsubsection{Cell encapsulation and culture}

- $70 \%$ Ethanol, Life Technologies

- Irgacure $^{\circledR} 2959$ (IC2959), BASF

- $\quad$ PBS (as above)

\subsubsection{Human prostate cancer LNCaP cell culture}

- LNCaP cells, ATCC CRL-1740

- RPMI medium 1640, L-glutamine, no phenol red, Life Technologies

- Fetal bovine serum (FBS), Life Technologies

- Penicillin-streptomycin, 10,000 U/ml, Life Technologies

- Trypsin-EDTA, no phenol red, Life Technologies

- $\quad$ PBS (as above)

\subsubsection{Human breast cancer MCF-7 cell culture}

- $\quad$ MCF7 cells, ATCC HTB-22

- Eagle's minimum essential medium (EMEM), L-glutamine, Life Technologies

- $\quad$ FBS (as above)

- Penicillin-streptomycin (as above)

- Insulin, Sigma-Aldrich

- Trypsin-EDTA (as above)

- $\quad$ PBS (as above)

\subsubsection{Assessment of cell viability}

- Fluorescein diacetate (FDA), Life Technologies

- Propidium iodide (PI), Life Technologies

- Acetone, Life Technologies

- $\quad$ PBS (as above) 


\subsubsection{Assessment of cell morphology}

- Paraformaldehyde (PFA), Sigma-Aldrich (danger)

- Triton X-100, Sigma-Aldrich

- Glycine, Sigma-Aldrich

- Bovine serum albumin, Sigma-Aldrich

- E-cadherin antibody, monoclonal (\#EP700Y), Life Technologies

- Alexa488-conjugated goat anti-rabbit antibody, polyclonal, Life Technologies

- Rhodamine 415-conjugated phalloidin, Life Technologies (hazardous)

- 4’,6-Diamidino-2-phenylindole (DAPI), Life Technologies

\subsubsection{Assessment of cell proliferation}

- Quant-iT ${ }^{\mathrm{TM}}$ Picogreen ${ }^{\circledR}$ ds DNA assay kit, Life Technologies

- Proteinase K, Life Technologies

- $\mathrm{Na}_{2} \mathrm{HPO}_{4}$, Merck Chemicals

- $\mathrm{NaH}_{2} \mathrm{PO}_{4} \times \mathrm{H}_{2} \mathrm{O}$, Merck Chemicals

- $\mathrm{Na}_{2}$ EDTA, Life Technologies

- Demineralised or ultrapure (MilliQ) water

\subsection{Equipment}

\subsubsection{GelMA synthesis}

- Round bottom flasks (500 $\mathrm{ml}$ volume)

- Laboratory magnetic stirrer with heating function

- Large magnetic stirring bar

- Chemical safety fume hood

- Temperature-controlled water bath

- Laboratory balance

- $50 \mathrm{ml}$ falcon tubes

- Laboratory glassware

- Laboratory benchtop centrifuge

- Dialysis membrane, 12 kDa molecular weight cut-off, Sigma-Aldrich

- Sterile syringes (50 $\mathrm{ml}$ volume) 
- Nalgene $^{\mathrm{TM}}$ Rapid-Flow ${ }^{\mathrm{TM}}$ sterile disposable filters with polyethersulfone (PES), $0.2 \mu \mathrm{m}$ pore size, Life Technologies

- Lyophiliser (freeze-dryer)

\subsubsection{Characterisation of GelMA functionalisation}

- Temperature-controlled water bath

- $15 \mathrm{ml}$ falcon tubes

- Clear 96-well plates

- Laboratory shaker/rocker plate

- Laboratory oven

- Microplate photometer

\subsubsection{Cell encapsulation and culture}

- Cell culture incubator

- Sterile cell culture flasks $\left(75 \mathrm{~cm}^{2}\right)$

- Biological safety cabinet

- Analytical balance

- Temperature-controlled water bath

- Laboratory benchtop centrifuge

- Teflon hydrogel casting mould, custom-made with circular recesses $(\varnothing=5 \mathrm{~mm}, \mathrm{~h}=2$ $\mathrm{mm}$ ); alternative design reported previously (Loessner et al. 2016)

- Microscope glass slides, ProSciTech

- Spatula

- Forceps

- CL-1000 ultraviolet (UV) crosslinker with $365 \mathrm{~nm}$ wavelength tubes, UVP

- 24-well plates, cell culture-treated

- Haemocytometer or cell counter

- $50 \mathrm{ml}$ falcon tubes

\subsubsection{Assessment of cell viability}

- Spatula

- 24-well plates, cell culture-treated

- Microscope glass slides (as above) 
- Standard fluorescence or confocal laser scanning microscope (CLSM), with FITC and TRITC filter sets

\subsubsection{Assessment of cell morphology}

- Spatula

- 24-well plates, cell culture-treated

- $0.2 \mu \mathrm{m}$ syringe filter units

- CLSM

\subsubsection{Assessment of cell proliferation}

- Spatula

- $2 \mathrm{ml}$ centrifuge tubes

- Heating block

- Laboratory benchtop centrifuge

- Black 96-well plates

- Laboratory shaker/rocker plate

- Fluorescence microplate reader

\subsection{Reagent setup}

\subsubsection{GelMA synthesis}

Prepare $5 \mathrm{M} \mathrm{NaOH}$ solution by dissolving $20 \mathrm{~g}$ of $\mathrm{NaOH}$ in $80 \mathrm{ml}$ of demineralised or ultrapure (MilliQ) water and adjust to a final volume of $100 \mathrm{ml}$.

\subsubsection{Characterisation of GelMA functionalisation}

Prepare $0.1 \mathrm{M} \mathrm{NaHCO}_{3}$ buffer by dissolving $8.4 \mathrm{~g}$ of $\mathrm{NaHCO}_{3}$ in 1 liter of demineralised or ultrapure (MilliQ) water and adjust the $\mathrm{pH}$ to 8.5 . Prepare $0.01 \%(\mathrm{wt} / \mathrm{vol})$ TNBS solution by diluting TNBS stock solution in demineralised or ultrapure (MilliQ) water in a chemical safety fume hood (1:500 dilution).

\subsubsection{Cell encapsulation and culture}

Prepare photoinitiator solution by dissolving IC2959 at $0.05 \%$ (wt/vol) in PBS by heating to $70{ }^{\circ} \mathrm{C}$ in a water bath protected from light for 10-15 min or until fully dissolved. 


\subsubsection{Medium for $\mathrm{LNCaP}$ cell culture}

Supplement RPMI with 5\% (vol/vol) FBS and $100 \mathrm{U} / \mathrm{ml}$ penicillin-streptomycin. Medium can be stored at $4{ }^{\circ} \mathrm{C}$ for $4-6$ weeks.

\subsubsection{Medium for MCF-7 cell culture}

Supplement EMEM with $10 \%$ (vol/vol) FBS, $100 \mathrm{U} / \mathrm{ml}$ penicillin-streptomycin and $0.01 \mathrm{mg} / \mathrm{ml}$ insulin. Medium can be stored at $4{ }^{\circ} \mathrm{C}$ for $4-6$ weeks.

\subsubsection{Assessment of cell viability}

Prepare a $10 \mathrm{mg} / \mathrm{ml}$ stock solution of FDA in PBS by dissolving $100 \mathrm{mg}$ of FDA in $10 \mathrm{ml}$ of acetone and store protected from light at $-20{ }^{\circ} \mathrm{C}$ for up to 1 year. Freshly prepare the required volume of the FDA/PI staining solution ( $1 \mathrm{ml}$ per sample) by adding $1 \mu \mathrm{l}$ of each stock solution to $998 \mu \mathrm{l}$ of PBS to obtain a final FDA and PI concentration of $10 \mu \mathrm{g} / \mathrm{ml}$ and $5 \mu \mathrm{g} / \mathrm{ml}$ respectively.

\subsubsection{Assessment of cell morphology}

Prepare a $4 \%(\mathrm{wt} / \mathrm{vol})$ solution of PFA dissolved in PBS according to your laboratory's standard procedures and store at $-20{ }^{\circ} \mathrm{C}$ for up to 1 year. Prepare a $0.2 \%$ (vol/vol) triton $\mathrm{X}-100$ solution by adding $20 \mu \mathrm{l}$ triton X-100 to $10 \mathrm{ml}$ of $4 \%$ (wt/vol) PFA solution while stirring and store at $4{ }^{\circ} \mathrm{C}$ up to 2 months (alternatively, prepare a $0.2 \%$ (vol/vol) triton X-100 solution by adding $20 \mu \mathrm{l}$ triton $\mathrm{X}-100$ to $10 \mathrm{ml}$ of PBS). Prepare a $0.1 \mathrm{M}$ glycine solution by dissolving $377 \mathrm{mg}$ of glycine in $50 \mathrm{ml}$ of PBS and store at $4{ }^{\circ} \mathrm{C}$ for up to 2 months. Prepare a $1 \%(\mathrm{wt} / \mathrm{vol})$ solution of BSA by dissolving $1 \mathrm{~g}$ of BSA in $100 \mathrm{ml}$ of PBS and store at $4{ }^{\circ} \mathrm{C}$ up to 2 months. Prepare a $5 \mathrm{mg} / \mathrm{ml}$ stock solution of DAPI by dissolving $10 \mathrm{mg}$ of DAPI in $2 \mathrm{ml}$ of PBS and store protected from light at $-20{ }^{\circ} \mathrm{C}$ for up to 1 year. It is recommended that the following solutions are filter-sterilised using $0.2 \mu \mathrm{m}$ syringe filter units before usage: $4 \%$ (wt/vol) PFA, glycine $0.1 \mathrm{M}$ and $1 \%(\mathrm{wt} / \mathrm{vol}) \mathrm{BSA}$ solutions. Prepare the following staining solutions immediately before usage: 1:400 dilution of E-cadherin antibody in 1\% (wt/vol) BSA solution, 1:1,000 dilution of Alexa488-conjugated anti-rabbit antibody in 1\% (wt/vol) BSA solution, $0.3 \mathrm{U} / \mathrm{ml}$ rhodamine 415 -conjugated phalloidin in $1 \%$ (wt/vol) BSA solution and $2.5 \mu \mathrm{g} / \mathrm{ml}$ DAPI in PBS.

\subsubsection{Assessment of cell proliferation}


Prepare phosphate-buffered EDTA (PBE) buffer containing $20 \mathrm{mM} \mathrm{Na} 2 \mathrm{HPO}_{4}, 30 \mathrm{mM}$ $\mathrm{NaH}_{2} \mathrm{PO}_{4} \times \mathrm{H}_{2} \mathrm{O}$ and $5 \mathrm{mM} \mathrm{Na} 2$ EDTA in $500 \mathrm{ml}$ of demineralised or ultrapure (MilliQ) water, adjust to $\mathrm{pH} 7.1$ and autoclave at $121^{\circ} \mathrm{C}$ for $15 \mathrm{~min}$. Prepare a $100 \mathrm{mg}$ stock solution of proteinase $\mathrm{K}$ in $10 \mathrm{ml}$ of $\mathrm{PBE}$ buffer and store at $4{ }^{\circ} \mathrm{C}$ up to 1 year. Prepare a fresh solution of $0.5 \mathrm{mg} / \mathrm{ml}$ proteinase $\mathrm{K}$ in PBE buffer for each experiment. Prepare a fresh PicoGreen dye solution following the manufacturer's instructions.

\section{Methods}

The step-by-step protocol for the preparation of the GelMA polymer, used to prepare hydrogelbased 3D cell culture models for cancer and stem cell research, as well as for tissue engineering applications, has been reported previously (Loessner et al. 2016). Our group developed quality control and validation procedures, for example to assess the degree of GelMA functionalisation and mechanical properties, to ensure reproducibility in in vitro and in vivo studies, with particular focus on ovarian cancer, cartilage tissue engineering, bone colonisation and vascular networks (Loessner et al. 2016). The methods described in this chapter report, for the first time, a step-by-step protocol for spheroid cultures for widely used prostate and breast cancer cells to establish in vitro 3D cancer models. In particular, the production of the GelMA polymer (Figure 1A), the encapsulation and culture of LNCaP and MCF-7 cells in 4\% (wt/vol) GelMAbased hydrogels (Figure 1B), as well as bioassays used to assess cell viability, morphology and proliferation are described (Figure 1C).

\subsection{GelMA synthesis}

Gelatin can be functionalised with photocrosslinkable methacryloyl groups by reaction with methacrylic anhydride (MAAh) to result in GelMA (Figure 1A). MAAh is hazardous and nust be handled with care. Suitable personal protective equipment is required, and the synthesis reaction, including all steps involving unsealed MAAh, must be performed in a chemical safety fume hood. Maintain gelatin and GelMA solutions at $40{ }^{\circ} \mathrm{C}$ between all steps to avoid thermal gelation (reversible), unless specified otherwise.

- Weigh 10-30 g of gelatin into a $500 \mathrm{ml}$ round bottom flask and add PBS to a final gelatin concentration of $10 \%$ (wt/vol). Add a magnetic stirring bar and place the round bottom flask into a water bath on a laboratory magnetic stirrer heated to $50{ }^{\circ} \mathrm{C}$ inside a chemical safety fume hood (Figure 2A-B). 
- Dissolve gelatin by moderately stirring for approximately $2 \mathrm{hrs}$ or until the solution appears clear and homogeneous (Figure 2C).

- Meanwhile, transfer a laboratory balance into the chemical safety fume hood. Weigh $0.6 \mathrm{~g}$ of MAAh per gram of gelatin into a clean glass beaker using a glass pipette.

- Increase the stirring speed as much as possible and carefully add MAAh. Continue stirring for $3 \mathrm{hrs}$ at $50{ }^{\circ} \mathrm{C}$ to facilitate the functionalisation of gelatin with photocrosslinkable methacryloyl groups (Figure 2D). Note 4.1.

- Aliquot the reaction mixture into $50 \mathrm{ml}$ falcon tubes.

- Pre-heat about $500 \mathrm{ml}$ of demineralised or ultrapure (MilliQ) water in a glass bottle using a water bath heated to $40{ }^{\circ} \mathrm{C}$ for about $15 \mathrm{~min}$.

- While the water is pre-heating, transfer the $50 \mathrm{~mL}$ falcon tubes containing the GelMA solution into a laboratory benchtop centrifuge and pellet unreacted MAAh by centrifugation at $3,500 \mathrm{~g}$ for $3 \mathrm{~min}$. Transfer the $50 \mathrm{~mL}$ falcon tubes into a chemical safety fume hood and decant the supernatant containing GelMA into a clean glass beaker. Discard the pellet. Add approximately one volume of pre-heated demineralised or ultrapure (MilliQ) water to the GelMA solution (Figure 2E).

- To remove by-products and salts, transfer the diluted GelMA solution into dialysis membrane (12 kDa molecular weight cut-off; Figure $2 \mathrm{~F})$ and dialyse at $40{ }^{\circ} \mathrm{C}$ against demineralised or ultrapure (MilliQ) water for 5-7 days protected from light. Change the water at least once daily. Dialysis is completed when the solution appears clear, and the odour of MAAh is no longer noticeable (Figure $2 \mathrm{G}$ ).

- Transfer the GelMA solution into a clean glass beaker and adjust the pH to 7.4 using $5 \mathrm{M} \mathrm{NaOH}$ (see Reagent setup).

- Transfer the neutralised GelMA solution into a biological safety cabinet, and sterilefilter using $0.2 \mu \mathrm{m}$ syringe filter units with a polyethersulfone (PES) membrane (most other membrane types will clog) into sterile $50 \mathrm{ml}$ falcon tubes. Freeze overnight at $80{ }^{\circ} \mathrm{C}$.

- Transfer frozen aliquots to a lyophiliser and freeze-dry for 5 days (screw caps need to be loosened slightly to allow gas exchange) or until GelMA is fully dehydrated. Store at $-20^{\circ} \mathrm{C}$ until usage (Figure $1 \mathrm{~A}$ ).

\subsection{Characterisation of GelMA functionalisation}


It is recommended to characterise the degree of functionalisation (DoF) of every newly synthesised GelMA batch to ensure reproducibility between batches. While both primary amines and hydroxyl-groups of gelatin react with MAAh to form methacrylamides and methacrylates respectively, over $90 \%$ of the functionalisation occurs at primary amines (Yue et al. 2015). As a viable alternative to ${ }^{1} \mathrm{H}-\mathrm{NMR}$ analysis, the method outlined in this chapter assesses the degree of amine functionalisation (DoAF) in GelMA as an approximation of the total DoF.

- Prepare $0.1 \mathrm{M} \mathrm{NaHCO}_{3}$ buffer and $0.01 \%$ (wt/vol) TNBS solution (see Reagent setup).

- Weigh $100 \mathrm{mg}$ of GelMA and unfunctionalised gelatin into two separate $15 \mathrm{ml}$ falcon tubes. Add $0.1 \mathrm{M} \mathrm{NaHCO}_{3}$ buffer to a concentration of $10 \mathrm{mg} / \mathrm{ml}$ respectively and dissolve by heating to $37^{\circ} \mathrm{C}$ in a water bath for approximately $1 \mathrm{hr}$, mixing occasionally until solutions appear clear and homogenous. Transfer $250 \mu \mathrm{l}$ of each solution to a new $15 \mathrm{ml}$ falcon tube and dilute with $4.75 \mathrm{ml} 0.1 \mathrm{M} \mathrm{NaHCO}_{3}$ buffer to obtain GelMA and gelatin concentrations of $500 \mu \mathrm{g} / \mathrm{ml}$ respectively. Note 4.2 .

- Prepare 1:2 dilution series of GelMA and gelatin solutions: $500 \mu \mathrm{g} / \mathrm{ml}, 250 \mu \mathrm{g} / \mathrm{ml}$, $125 \mu \mathrm{g} / \mathrm{ml}, 62.5 \mu \mathrm{g} / \mathrm{ml}, 31.25 \mu \mathrm{g} / \mathrm{ml}$ and $0 \mu \mathrm{g} / \mathrm{ml}$, with at least $600 \mu \mathrm{l}$ final volume per dilution.

- For triplicate measurements, transfer three times $200 \mu \mathrm{l}$ of each GelMA and gelatin dilution into a clear 96-well plate. Add $100 \mu \mathrm{l}$ of $0.01 \%$ (wt/vol) TNBS solution to each well and mix on a shaker/rocker plate for 5 min protected from light.

- Incubate at $37^{\circ} \mathrm{C}$ in a laboratory oven for $2 \mathrm{hrs}$ protected from light.

- Measure the absorbance at $335 \mathrm{~nm}$ using a microplate photometer.

- Subtract the mean absorbance of the blanks $(0 \mu \mathrm{g} / \mathrm{ml})$ from each value. Calculate the mean absorbance of triplicate measurements and plot linear regression lines for each GelMA and gelatin and ensure $\mathrm{R}^{2} \geq 0.95$. Determine the slope of both regression lines and calculate the DoAF as DoAF $=\left(1-\frac{m_{\text {GelMA }}}{m_{\text {gelatin }}}\right) 100 \%$.

\subsection{Cell encapsulation}

The method described herein focuses on the encapsulation of LNCaP or MCF-7 cells in $4 \%$ (wt/vol) GelMA-based hydrogels for application as in vitro 3D cancer models (Figure 1B). The handling of cells is performed in a biological safety cabinet using only sterile equipment and 
reagents. Before commencing this procedure, expand $\mathrm{LNCaP}$ and $\mathrm{MCF}-7$ cells in tissue culture flasks to approximately $70-80 \%$ confluency.

- Sterilise the Teflon casting mould, microscope glass slides and spatula by spraying with $70 \%$ (wt/vol) ethanol, followed by air-drying.

- Prepare $0.05 \%$ (wt/vol) photoinitiator solution (see Reagent setup).

- To weigh in GelMA without compromising sterility, determine the weight of a sterile $50 \mathrm{ml}$ falcon tube and add GelMA in a biological safety cabinet using sterile forceps. Weigh the tube again and determine the amount of GelMA by subtracting the weight of the empty $50 \mathrm{ml}$ falcon tube.

- Add photoinitiator solution to a final GelMA concentration of 4\% (wt/vol). Dissolve this GelMA precursor solution in a water bath heated to $37{ }^{\circ} \mathrm{C}$ for approximately $3 \mathrm{hrs}$ or until solution appears clear and homogenous.

- Once GelMA is fully dissolved, detach LNCaP or MCF-7 cells using trypsin-EDTA according to your laboratory's standard procedures, and wash the cell pellet with $20 \mathrm{ml}$ of PBS to remove traces of trypsin. Centrifuge again and discard the supernatant. Resuspend the cell pellet in the respective culture medium (see Reagent setup) and determine the cell number using a haemocytometer or cell counter.

- Calculate the required number of cells $\left(n_{\text {cells }}\right)$ based on the volume of GelMA precursor solution $\left(V_{\text {GelMA }}\right)$ and the desired cell density (here: $3.5 \times 10^{5}$ cells/ml GelMA precursor solution) using the equation $n_{\text {cells }}=V_{\text {GelMA }} \times 3.5 \times 10^{5}$ cells $/ \mathrm{ml}$. Pellet the required amount of cells by centrifugation, remove the supernatant, and add the GelMA precursor solution to a the cell density of $3.5 \times 10^{5}$ cells $/ \mathrm{ml}$. Mix carefully by pipetting up and down to yield a single cell suspension while avoiding introduction of air bubbles.

Note 4.3.

- Transfer the cell-containing hydrogel precursor solution into the resesses of the sterile casting mould and cover with a sterile glass slide. Avoid the introduction of air bubbles. Note 4.4.

- Photocrosslink the cell-containing hydrogel precursor solution by exposure to $365 \mathrm{~nm}$ at $2.5 \mathrm{~mW} / \mathrm{cm}^{2} \mathrm{UV}$ light for $12 \mathrm{~min}$. Note that exposure times may vary depending on the intensity of the $365 \mathrm{~nm}$ light source and the design of the casting mould. Optimise exposure times to yield hydrogels with a Young's modulus of approximately $5 \mathrm{kPa}$. 
- Culture cell-laden hydrogel constructs in suitable culture medium (see Reagent setup) using 24-well plates at $37{ }^{\circ} \mathrm{C}$ and $5 \% \mathrm{CO}_{2}$ (Figure 1B).

\subsection{Assessment of cell viability}

Living and dead cells encapsulated in GelMA-based hydrogels can be visualised with a fluorescence microscope using a FDA/PI staining. It is recommended to assess cell viability one day after cell encapsulation and at any other desired time point. This procedure represents an endpoint analysis and cell-laden hydrogels may be discarded or employed for immunostaining (see 3.5.) afterwards.

- Prepare FDA/PA staining solution (see Reagent setup).

- Carefully remove cell-laden hydrogels from culture medium using a sterile spatula and wash in $1 \mathrm{ml}$ PBS for $10 \mathrm{~min}$ at room temperature (RT) in a 24-well plate. Discard culture medium.

- Incubate in $1 \mathrm{ml} \mathrm{FDA/PI} \mathrm{staining} \mathrm{solution} \mathrm{for} 10 \mathrm{~min}$ at RT.

- Wash in $1 \mathrm{ml}$ PBS for $5 \mathrm{~min}$ at RT.

- Remove from PBS and place cell-laden hydrogel on a microscope glass slide.

- Immediately capture images of living (fluorescein excitation/emission maxima: 490/525 nm) and dead (PI excitation/emission maxima: 493/636 nm) cells using a standard fluorescence microscope or CLSM at 4-20x magnification as desired.

\subsection{Assessment of cell morphology}

To visualise the morphology of hydrogel-encapsulated cells and spheroids, (immuno-) fluorescent staining of an epithelial cell marker (here: E-cadherin) as well as the cytoskeleton and cell nuclei can be used and imaged by CLSM.

- Prepare 4\% (wt/vol) PFA, 0.2\% (vol/vol) triton X-100, $0.1 \mathrm{M}$ glycine and E-cadherin antibody solutions (see Reagent setup).

- Remove cell-laden hydrogels from culture medium using a sterile spatula and wash in $1 \mathrm{ml}$ PBS for $10 \mathrm{~min}$ at RT. Discard culture medium.

- Fix and permeabilise samples with $1 \mathrm{ml} 4 \%$ (wt/vol) PFA containing $0.2 \%$ (vol/vol) triton X-100 in a 24-well plate on a shaker/rocker plate for $30 \mathrm{~min}$ at RT. Note 4.5.

- Wash with $1 \mathrm{ml} 0.1 \mathrm{M}$ glycine solution, then twice with $1 \mathrm{ml}$ PBS for 5 min each at RT. 
- Incubate in E-cadherin antibody solution overnight at $4{ }^{\circ} \mathrm{C}$ protected from light.

- Prepare Alexa488-conjugated anti-rabbit antibody, rhodamine 415-conjugated phalloidin and DAPI solutions (see Reagent setup).

- Wash twice with $1 \mathrm{ml}$ of PBS for 5 min each at RT.

- Incubate in Alexa488-conjugated anti-rabbit antibody solution (see Reagent setup) for $1 \mathrm{hr}$ at RT protected from light.

- Incubate in rhodamine 415-conjugated phalloidin solution for $1 \mathrm{hr}$ at RT protected from light.

- Wash twice with $1 \mathrm{ml}$ of PBS for 5 min each at RT.

- Incubate in DAPI for 40-50 min at RT protected from light.

- Wash twice with $1 \mathrm{ml}$ of PBS for 5 min each at RT.

- Using a CLSM, image with a 10/20x oil objective to acquire $z$-stacks with a slice thickness of 2-5 $\mu \mathrm{m}$ (Figure 3C) and generate maximal intensity projections as reported previously (Loessner et al. 2016).

\subsection{Assessment of cell proliferation}

The total DNA content of cell-laden GelMA-based hydrogels can be assessed using a QuantiT $^{\mathrm{TM}}$ Picogreen ${ }^{\circledR}$ ds DNA assay kit following sample digestion with proteinase K. The increase in DNA content over the culture duration corresponds to an increase in cell number. To investigate the proliferation of LNCaP or MCF-7 cells in GelMA-based hydrogels, this method can be performed at day 1 and at the endpoint of culture, for example at day 14 (Loessner et al. 2013).

- Prepare PBE buffer and proteinase K solution (see Reagent setup).

- At the desired time point, transfer cell-laden hydrogels (triplicate or more per experimental condition) to $2 \mathrm{ml}$ centrifuge tubes using a spatula. Note that samples may be frozen at $-20{ }^{\circ} \mathrm{C}$ for later processing or used immediately.

- Incubate cell-laden hydrogels in $500 \mu 1$ proteinase $\mathrm{K}$ solution overnight at $65{ }^{\circ} \mathrm{C}$ in a heating block or until fully digested.

- Prepare DNA standards in PBE buffer with the provided Lambda DNA standard by diluting 1:2 over the following concentrations: $2,000 \mathrm{ng} / \mathrm{ml}, 1,000 \mathrm{ng} / \mathrm{ml}, 500 \mathrm{ng} / \mathrm{ml}$, $250 \mathrm{ng} / \mathrm{ml}, 125 \mathrm{ng} / \mathrm{ml}, 62.5 \mathrm{ng} / \mathrm{ml}, 31.25 \mathrm{ng} / \mathrm{ml}$ and $0 \mathrm{ng} / \mathrm{ml}$, with at least $300 \mu$ final volume per dilution. 
- Prepare the PicoGreen dye solution (see Reagent setup; for triplicate measurements, $300 \mu 1$ per sample and Lambda DNA standard are required).

- Samples may need to be diluted 1:10, 1:20 or 1:50 in PBE buffer, according to the expected DNA content. Note 4.6.

- For triplicate measurements, transfer three times $100 \mu \mathrm{l}$ of each (diluted) sample and Lambda DNA standard to a black 96-well plate. Note 4.7.

- Add $100 \mu \mathrm{l}$ of PicoGreen dye solution to each well and incubate for 5 min at RT protected from light on a shaker/rocker plate.

- Measure fluorescent signals (excitation/emission maxima: 480/520 nm) using a fluorescence plate reader.

- Determine DNA concentrations of the sample digests compared to a linear regression line of the Lambda DNA standard. To determine the total DNA content of a sample, multiply the obtained DNA concentrations with the dilution factor used and the total digest volume (here: $0.5 \mathrm{ml}$; Figure 3B).

\section{Notes}

4.1. Note that the stirring speed may vary depending on the setup and volume used. As a general guideline, the solution turns opaque after addition of MAAh (Figure 2D). If visible phase separation occurs, increase the stirring speed or use an overhead stirrer.

4.2. Alternatively, GelMA and gelatin may be directly dissolved at $500 \mu \mathrm{g} / \mathrm{ml}$ in $\mathrm{NaHCO}_{3}$ buffer. However, accuracy may be affected if GelMA and gelatin are dissolved at such low concentrations.

4.3. Other GelMA and IC 2925 concentrations and cell densities tested were reported previously (Loessner et al. 2016).

4.4. Avoid introduction of air bubbles as oxygen may partially inhibit the polymerisation of GelMA.

4.5. Fixation and permeabilisation can be carried out in two individual steps. Samples can be stored in $4 \%$ (wt/vol) PFA in PBS at $4{ }^{\circ} \mathrm{C}$ for up to 1 month. When ready to proceed with the 
fluorescent staining, permeabilise samples in $0.2 \%$ (vol/vol) triton X-100 in PBS for $30 \mathrm{~min}$ at RT.

4.6. It is recommended to optimise the dilution factor using 1-2 samples with the lowest and highest expected DNA content respectively, for example from day 1 and day 14. The final DNA concentration in the diluted digest should be in the linear range between 0 and $2,000 \mathrm{ng} / \mathrm{ml}$.

4.7. If more than one black 96 -well plate is needed, it is recommended to prepare a Lambda DNA standard curve for each individual plate.

\section{References}

Abbott RD, Kaplan DL (2015) Strategies for improving the physiological relevance of human $\begin{array}{llllll}\text { engineered } & \text { tissues. } & \text { Trends } & \text { Biotechnol } & 33 & \text { (7):401-407. }\end{array}$ doi:10.1016/j.tibtech.2015.04.003

Albini A (2016) Extracellular Matrix Invasion in Metastases and Angiogenesis: Commentary on the Matrigel "Chemoinvasion Assay". Cancer Res 76 (16):4595-4597. doi:10.1158/0008-5472.CAN-16-1971

Anastasov N, Hofig I, Radulovic V, Strobel S, Salomon M, Lichtenberg J, Rothenaigner I, Hadian K, Kelm JM, Thirion C, Atkinson MJ (2015) A 3D-microtissue-based phenotypic screening of radiation resistant tumor cells with synchronized chemotherapeutic treatment. BMC Cancer 15:466. doi:10.1186/s12885-015-1481-9

Bersani F, Lee J, Yu M, Morris R, Desai R, Ramaswamy S, Toner M, Haber DA, Parekkadan B (2014) Bioengineered implantable scaffolds as a tool to study stromal-derived factors in metastatic cancer models. Cancer Res 74 (24):7229-7238. doi:10.1158/00085472.CAN-14-1809

Bischel LL, Casavant BP, Young PA, Eliceiri KW, Basu HS, Beebe DJ (2014) A microfluidic coculture and multiphoton FAD analysis assay provides insight into the influence of the bone microenvironment on prostate cancer cells. Integr Biol (Camb) 6 (6):627-635. doi:10.1039/c3ib40240a

Bray LJ, Binner M, Holzheu A, Friedrichs J, Freudenberg U, Hutmacher DW, Werner C (2015) Multi-parametric hydrogels support 3D in vitro bioengineered microenvironment 
models of tumour angiogenesis. Biomaterials 53:609-620. doi:10.1016/j.biomaterials.2015.02.124

Chambers KF, Mosaad EM, Russell PJ, Clements JA, Doran MR (2014) 3D Cultures of prostate cancer cells cultured in a novel high-throughput culture platform are more resistant to chemotherapeutics compared to cells cultured in monolayer. PLoS One 9 (11):e111029. doi:10.1371/journal.pone.0111029

Chaudhuri O, Koshy ST, Branco da Cunha C, Shin JW, Verbeke CS, Allison KH, Mooney DJ (2014) Extracellular matrix stiffness and composition jointly regulate the induction of malignant phenotypes in mammary epithelium. Nature materials 13 (10):970-978. doi:10.1038/nmat4009

DelNero P, Lane M, Verbridge SS, Kwee B, Kermani P, Hempstead B, Stroock A, Fischbach C (2015) 3D culture broadly regulates tumor cell hypoxia response and angiogenesis via pro-inflammatory pathways. Biomaterials 55:110-118. doi:10.1016/j.biomaterials.2015.03.035

Dudley DT, Li XY, Hu CY, Kleer CG, Willis AL, Weiss SJ (2014) A 3D matrix platform for the rapid generation of therapeutic anti-human carcinoma monoclonal antibodies. Proc Natl Acad Sci U S A 111 (41):14882-14887. doi:10.1073/pnas.1410996111

Engel BJ, Constantinou PE, Sablatura LK, Doty NJ, Carson DD, Farach-Carson MC, Harrington DA, Zarembinski TI (2015) Multilayered, Hyaluronic Acid-Based Hydrogel Formulations Suitable for Automated 3D High Throughput Drug Screening of Cancer-Stromal Cell Cocultures. Adv Healthc Mater 4 (11):1664-1674. doi:10.1002/adhm.201500258

Fong EL, Wan X, Yang J, Morgado M, Mikos AG, Harrington DA, Navone NM, FarachCarson MC (2016) A 3D in vitro model of patient-derived prostate cancer xenograft for controlled interrogation of in vivo tumor-stromal interactions. Biomaterials 77:164172. doi:10.1016/j.biomaterials.2015.10.059

Gao D, Vela I, Sboner A, Iaquinta PJ, Karthaus WR, Gopalan A, Dowling C, Wanjala JN, Undvall EA, Arora VK, Wongvipat J, Kossai M, Ramazanoglu S, Barboza LP, Di W, Cao Z, Zhang QF, Sirota I, Ran L, MacDonald TY, Beltran H, Mosquera JM, Touijer KA, Scardino PT, Laudone VP, Curtis KR, Rathkopf DE, Morris MJ, Danila DC, Slovin SF, Solomon SB, Eastham JA, Chi P, Carver B, Rubin MA, Scher HI, Clevers H, Sawyers CL, Chen Y (2014) Organoid cultures derived from patients with advanced prostate cancer. Cell 159 (1):176-187. doi:10.1016/j.cell.2014.08.016 
Joyce JA, Pollard JW (2009) Microenvironmental regulation of metastasis. Nat Rev Cancer 9 (4):239-252. doi:nrc2618 [pii] 10.1038/nrc2618

Kaemmerer E, Melchels FP, Holzapfel BM, Meckel T, Hutmacher DW, Loessner D (2014) Gelatine methacrylamide-based hydrogels: an alternative three-dimensional cancer cell culture system. Acta Biomater 10 (6):2551-2562. doi:10.1016/j.actbio.2014.02.035

Karthaus WR, Iaquinta PJ, Drost J, Gracanin A, van Boxtel R, Wongvipat J, Dowling CM, Gao D, Begthel H, Sachs N, Vries RG, Cuppen E, Chen Y, Sawyers CL, Clevers HC (2014) Identification of multipotent luminal progenitor cells in human prostate organoid cultures. Cell 159 (1):163-175. doi:10.1016/j.cell.2014.08.017

Levental KR, Yu H, Kass L, Lakins JN, Egeblad M, Erler JT, Fong SF, Csiszar K, Giaccia A, Weninger W, Yamauchi M, Gasser DL, Weaver VM (2009) Matrix crosslinking forces tumor progression by enhancing integrin signaling. Cell 139 (5):891-906. doi:10.1016/j.cell.2009.10.027

Levett PA, Melchels FP, Schrobback K, Hutmacher DW, Malda J, Klein TJ (2014) A biomimetic extracellular matrix for cartilage tissue engineering centered on photocurable gelatin, hyaluronic acid and chondroitin sulfate. Acta Biomater 10 (1):214-223. doi:10.1016/j.actbio.2013.10.005

Loessner D, Holzapfel BM, Clements JA (2014) Engineered microenvironments provide new insights into ovarian and prostate cancer progression and drug responses. Advanced drug delivery reviews 79-80:193-213. doi:10.1016/j.addr.2014.06.001

Loessner D, Meinert C, Kaemmerer E, Martine LC, Yue K, Levett PA, Klein TJ, Melchels FP, Khademhosseini A, Hutmacher DW (2016) Functionalization, preparation and use of cell-laden gelatin methacryloyl-based hydrogels as modular tissue culture platforms. Nature protocols 11 (4):727-746. doi:10.1038/nprot.2016.037

Loessner D, Rizzi SC, Stok KS, Fuehrmann T, Hollier B, Magdolen V, Hutmacher DW, Clements JA (2013) A bioengineered 3D ovarian cancer model for the assessment of peptidase-mediated enhancement of spheroid growth and intraperitoneal spread. Biomaterials 34 (30):7389-7400. doi:10.1016/j.biomaterials.2013.06.009

Mak M, Kamm RD, Zaman MH (2014) Impact of dimensionality and network disruption on microrheology of cancer cells in 3D environments. PLoS Comput Biol 10 (11):e1003959. doi:10.1371/journal.pcbi.1003959 
Nyga A, Neves J, Stamati K, Loizidou M, Emberton M, Cheema U (2016) The next level of 3D tumour models: immunocompetence. Drug Discov Today. doi:10.1016/j.drudis.2016.04.010

Onodera Y, Nam JM, Bissell MJ (2014) Increased sugar uptake promotes oncogenesis via EPAC/RAP1 and O-GlcNAc pathways. J Clin Invest 124 (1):367-384. doi:10.1172/JCI63146

Peela N, Sam FS, Christenson W, Truong D, Watson AW, Mouneimne G, Ros R, Nikkhah M (2016) A three dimensional micropatterned tumor model for breast cancer cell migration studies. Biomaterials 81:72-83. doi:10.1016/j.biomaterials.2015.11.039

Polacheck WJ, German AE, Mammoto A, Ingber DE, Kamm RD (2014) Mechanotransduction of fluid stresses governs 3D cell migration. Proc Natl Acad Sci U S A 111 (7):24472452. doi:10.1073/pnas.1316848111

Rijal G, Li W (2016) 3D scaffolds in breast cancer research. Biomaterials 81:135-156. doi:10.1016/j.biomaterials.2015.12.016

Sabhachandani P, Motwani V, Cohen N, Sarkar S, Torchilin V, Konry T (2016) Generation and functional assessment of 3D multicellular spheroids in droplet based microfluidics platform. Lab Chip 16 (3):497-505. doi:10.1039/c5lc01139f

Sieh S, Taubenberger AV, Lehman ML, Clements JA, Nelson CC, Hutmacher DW (2014) Paracrine interactions between LNCaP prostate cancer cells and bioengineered bone in 3D in vitro culture reflect molecular changes during bone metastasis. Bone 63:121-131. doi:10.1016/j.bone.2014.02.001

Singh M, Mukundan S, Jaramillo M, Oesterreich S, Sant S (2016) Three-Dimensional Breast Cancer Models Mimic Hallmarks of Size-Induced Tumor Progression. Cancer Res 76 (13):3732-3743. doi:10.1158/0008-5472.CAN-15-2304

Taubenberger AV, Bray LJ, Haller B, Shaposhnykov A, Binner M, Freudenberg U, Guck J, Werner C (2016) 3D extracellular matrix interactions modulate tumour cell growth, invasion and angiogenesis in engineered tumour microenvironments. Acta Biomater 36:73-85. doi:10.1016/j.actbio.2016.03.017

Yue K, Trujillo-de Santiago G, Alvarez MM, Tamayol A, Annabi N, Khademhosseini A (2015) Synthesis, properties, and biomedical applications of gelatin methacryloyl (GelMA) hydrogels. Biomaterials 73:254-271. doi:10.1016/j.biomaterials.2015.08.045

Zhu W, Wang M, Fu Y, Castro NJ, Fu SW, Zhang LG (2015) Engineering a biomimetic threedimensional nanostructured bone model for breast cancer bone metastasis study. Acta Biomater 14:164-174. doi:10.1016/j.actbio.2014.12.008 


\section{Figure legends}

Figure 1: Schematic illustrating GelMA production and application as 3D cancer model.

(A) GelMA is synthesised by a reaction of gelatin and methacrylic anhydride (MAAh). Following dialysis to remove reaction by-products and salts, the solution is lyophilised resulting in dry GelMA foam. To control the GelMA quality, thus ensuring high reproducibility between batches, the degree of functionalisation is assessed with a 2,4,6trinitrobenzenesulfonic acid (TNBS) assay. (B) To prepare cell-laden hydrogels, GelMA is dissolved in PBS containing the photoinitiator Irgacure ${ }^{\circledR} 2959$ (IC2959) and mixed with cells (LNCaP or MCF-7). The cell-containing precursor solution is cast into a Teflon mould and photocrosslinked to form cell-laden hydrogel constructs $(4 \mathrm{~mm} \times 4 \mathrm{~mm} \times 2 \mathrm{~mm})$. (C) Cellladen hydrogel constructs are cultured over a certain period of time, for example 14 days, to allow spheroid formation for use as in vitro 3D cancer model. The effects of novel drug candidates using this 3D cancer model can be investigated through the assessment of cell morphology, viability and proliferation.

Figure 2. GelMA functionalisation and dialysis. (A-B) Gelatin is dissolved in PBS in a round bottom flask with a magnetic stirring bar placed inside a water bath that is heated to $50{ }^{\circ} \mathrm{C}$. For large reaction volumes (up to 1 litre as depicted), an overhead stirrer with propeller agitator is recommended. (C) After approximately $2 \mathrm{hrs,} \mathrm{the} \mathrm{mixture} \mathrm{appears} \mathrm{clear,} \mathrm{indicating} \mathrm{that} \mathrm{gelatin}$ is completely dissolved. (D) While stirring, methacrylic anhydride (MAAh) is added and the solution turns opaque. (E) After $3 \mathrm{hrs}$, the solution is transferred into $50 \mathrm{ml}$ tubes and unreacted MAAh is removed by centrifugation at 3,500 $\mathrm{g}$ for $3 \mathrm{~min}$; an opaque and viscous pellet is visible. (F) The GelMA-containing supernatant is decanted into a glass beaker, diluted with demineralised water and transferred into a dialysis membrane. (G) The dialysis is carried out at $40{ }^{\circ} \mathrm{C}$ against a large volume of demineralised water for 5-7 days in a chemical safety fume hood, with daily water changes, until the GelMA solution appears clear.

Figure 3. Application of GelMA-based hydrogels as in vitro 3D cancer model. (A) Prostate cancer LNCaP and breast cancer MCF-7 cells are encapsulated within GelMA-based hydrogels (4\% (wt/vol) polymer concentration). After 1 day, cell viability is assessed by confocal microscopy performing a live/dead staining. Fluorescein diacetate stains living cells (green), and propidium iodide identifies dead cells (red). Both LNCaP and MCF-7 cells have a cell viability of $>95 \%$. (B) After 14 days, the DNA content is determined using a Picogreen ${ }^{\circledR} \mathrm{ds}$ 
DNA assay kit ( $\mathrm{n}=3$ using triplicate hydrogel samples; mean \pm SEM). Both LNCaP and MCF-7 cells have a similar DNA content. (C) After 14 days, cell morphology is assessed by confocal microscopy staining the epithelial cell marker E-cadherin (green), the cytoskeleton (red) and cell nuclei (blue). 